Kamile Miranda Lacerda ${ }^{1}$

Rita de Cássia Pereira Fernandes ${ }^{1}$

Leticia Coelho da Costa Nobre ${ }^{2}$

Paulo Gilvane Lopes Pena ${ }^{1}$

\section{A (in)visibilidade do acidente de trabalho fatal entre as causas externas: estudo qualitativo}

\author{
The (in)visibility of the fatal work-related injury as an external \\ cause of accidents: a qualitative study
}

${ }^{1}$ Universidade Federal da Bahia, Programa de Pós-Graduação Saúde, Ambiente e Trabalho. Salvador, BA, Brasil.

${ }^{2}$ Secretaria de Saúde do Estado da Bahia, Diretoria de Vigilância e Atenção à Saúde do Trabalhador. Salvador, BA, Brasil.

Contato:

Kamile Miranda Lacerda

E-mail:

milelacerda@gmail.com

Trabalho desenvolvido a partir da dissertação de mestrado de Kamile Miranda Lacerda intitulada Acidente de trabalho, precarização e desproteção social: elementos para uma discussão sobre morte e trabalho, defendida em 2012 no Programa de Pós-Graduação em Saúde, Ambiente e Trabalho da Faculdade de Medicina da Bahia da Universidade Federal da Bahia.

O presente estudo recebeu financiamento parcial para a sua realização na etapa de coleta dos dados, com recursos do Convênio do Ministério da Saúde (Fundo Nacional de Saúde)/Fundacentro (Centro Regional da Bahia), Portaria no $\%$ 0158/2004, e da Fundacentro (Programa de Melhoria da Qualidade das Estatísticas de Acidentes e Doenças do Trabalho).

Os autores declaram que não há conflitos de interesses e que o trabalho não foi apresentado em reunião científica.

Recebido: 14/09/2012

Revisado: 17/05/2014

Aprovado: 20/06/2014

\section{Resumo}

Objetivo: descrever o trabalho das vítimas dos acidentes fatais e as circunstâncias desses óbitos relacionados com o trabalho ocorridos em 2004, em Salvador, Bahia. Métodos: coleta de dados realizada através de questões semiabertas obtidas em entrevista domiciliar com os familiares das vítimas, por meio da autópsia verbal (AV). A análise de conteúdo foi empregada na análise das narrativas. A reconstituição dos 91 acidentes de trabalho (AT) é apresentada em duas seções temáticas: a caracterização do trabalho do acidentado e a circunstância da morte. Resultados: evidenciou-se a presença marcante do trabalho precário mesmo entre aqueles com vínculo formal, mas essas condições são especialmente flagrantes entre aqueles não regulamentados. A extensão da jornada de trabalho não decorreu de livre escolha, mas de estratégia para auferir a renda mínima necessária. O espaço da rua emergiu como local de AT típico não apenas de AT de trajeto. A morte no trânsito e sua relação com o trabalho, fenômeno ainda pouco explorado, foi evidenciada, além da identificação de homicídio como circunstância de morte decorrente do trabalho precário. Conclusões: a prevenção da morte e da violência no trabalho requer uma ação integrada das políticas setoriais. A autópsia verbal mostrou-se técnica promissora na produção de informações sobre as causas dos AT, podendo contribuir para a superação da subnotificação.

Palavras-chave: acidentes de trabalho; causas externas; trabalho precário; saúde do trabalhador; autópsia verbal.

\begin{abstract}
Objective: to describe the fatal accident victims' work and the circumstances of work-related deaths in Salvador, Bahia state, Brazil, in 2004. Methods: data collection by means of semi-open questionnaires applied to the victims' families in household interviews, through verbal autopsy (VA). Content analysis was applied to the narratives. The reconstruction of the 91 work accidents (WA) is presented in two thematic sections: the victims' work and their death circumstances. Results: the strong presence of precarious working conditions, even among those in formal jobs, was evident, but it was especially obvious among non-registered workers. In order to earn the necessary minimum income, they worked longer hours. The streets emerged as a typical WA spot, in contrast to being classified as a commuting accident. Traffic deaths and its relation to work, a phenomenon that has not been sufficiently studied, are evidenced along with murder as circumstances of death caused by precarious working conditions. Conclusions: preventing death and violence at the workplace demands integrated actions. Verbal autopsy has proved to be a promising technique to produce information on the WA causes, and it can help decrease underreporting.
\end{abstract}

Keywords: work-related accidents; external causes; precarious employment; workers' health; verbal autopsy. 


\section{Introdução}

O Acidente de Trabalho (AT) representa um grave problema de saúde pública (RUIZ; BARBOZA; SOLER, 2004) e esse fato vem se transformando e ganhando maior complexidade no cenário contemporâneo, no qual incidem condições precárias de trabalho, informalidade e trabalho no espaço da rua. Além disso, a complexa interação entre o trabalho e o fenômeno da violência torna-se relevante e tudo isso pode resultar em um panorama de exposição ocupacional com nova configuração (GOMEZ, 2005).

Lourenço (2009, p. 202) registra que “[...] o Brasil ainda é um recordista mundial de acidentes de trabalho, com três mortes a cada duas horas e três acidentes não fatais a cada um minuto". Estatísticas mais recentes da Previdência Social contabilizam que, em 2012, foram consolidados os dados de 724.169 acidentes de trabalho no Brasil, sendo 2.731 casos com óbito (BRASIL, 2012).

Para Nobre (2007, p. 22), o AT é um "fenômeno socialmente determinado, previsível e prevenível”. A legislação previdenciária classifica os AT em: "acidente típico - aquele que ocorre a serviço da empresa" e "[...] acidente de trajeto - aquele que ocorre no momento em que o trabalhador desloca-se para ou do local de trabalho e nos horários das refeições". Ainda, para fins de concessão dos benefícios acidentários, equipara-se ao AT a "doença do trabalho" (BRASIL, 2009).

Apesar do enquadramento legal e conceitual do AT, sua subnotificação constitui um grande problema no país. Cordeiro et al. (2005, p. 255) chegam a estimar que "[...] para cada dez acidentes de trabalho ocorridos, apenas um é notificado no Brasil”. Essa subnotificação acontece mesmo quando se trata do AT que leva à morte do trabalhador, uma vez que muitos óbitos não têm sua relação com o trabalho estabelecida e/ou registrada nos sistemas de informação (WALDVOGEL, 2003; MINAYO-GOMEZ; MACHADO; PENA, 2011).

Nesse contexto, Hennington, Cordeiro e Moreira Filho (2004, p. 610) lembram que "não existe um sistema único que centralize as informações sobre o AT no país", fato que prejudica a quantificação dos acidentes relacionados ao trabalho. Nos casos fatais, conta-se com o Sistema de Informação sobre Mortalidade (SIM) do Ministério da Saúde para o total dos acidentes e os registros das Comunicações de Acidentes de Trabalho (CAT) utilizados pelo Instituto Nacional do Seguro Social (INSS) da Previdência Social, restrito à população trabalhadora coberta pelo seguro acidentário (GOMEZ, 2005). Frequentemente, esses acidentes fatais aparecem nas estatísticas oficiais somente como homicídios, mortes no trânsito ou como acidentes em geral, contribuindo para a invisibilidade das situações adversas de trabalho responsáveis pela sua ocorrência.

Considerando as novas características do trabalho e a subnotificação do AT, o objetivo deste ensaio é descrever o trabalho das vítimas dos acidentes fatais e as circunstâncias desses óbitos relacionados com o trabalho ocorridos em 2004, em Salvador, Bahia.

\section{Métodos}

Neste estudo qualitativo foi utilizada como técnica para análise dos dados a análise de conteúdo, visando reconstituir as circunstâncias das mortes e sua relação com o trabalho através das narrativas de familiares, obtidas durante o inquérito domiciliar por meio da autópsia verbal (AV), em coleta realizada em 2004, em Salvador.

No estudo quantitativo que descreve os 91 acidentes de trabalho identificados, abordam-se detalhadamente os aspectos metodológicos e diferentes etapas seguidas pelos autores para sua realização (LACERDA; FERNANDES; NOBRE, 2014).

Embora a maior parte do questionário utilizado no estudo de base (NOBRE, 2007) fosse composto por perguntas fechadas com múltipla escolha, foram incluídas perguntas semiabertas para obterem-se informações mais completas sobre os óbitos e, assim, auxiliar na reconstituição e reclassificação da causa básica do óbito. Essa técnica, mais conhecida como autópsia verbal (AV), tem sido utilizada em áreas com elevada subnotificação de óbitos, visando esclarecimento de óbitos de causa mal definida (BRASIL, 2008).

Com isso foi possível reconstituir as circunstâncias das mortes e sua relação com o trabalho, através das narrativas de familiares obtidas com as seguintes questões semiabertas: "Você poderia me contar o que aconteceu com o Sr./Sra. ... que o levou à morte?"; "O que ele estava fazendo?"; "Se você pudesse dizer ou fazer alguma coisa para evitar novas mortes como essa, o que sugeriria? O que você acha que poderia ser feito para evitar outros casos como esse?"; "Vocês procuraram algum outro órgão público? Se sim, qual, para resolver o que e como foram atendidos?"

$\mathrm{O}$ conteúdo das respostas às questões citadas acima foi "tratado em profundidade" (MACHADO, 1991, p. 54), utilizando-se a análise de conteúdo como abordagem qualitativa e técnica de investigação. Essa técnica, através de uma descrição do conteúdo, tem por finalidade a interpretação da mensagem manifesta nos materiais escritos (BARDIN, 2009).

Os discursos dos familiares, majoritariamente companheiras e cônjuges dos trabalhadores, como "meio de expressão do sujeito" (CAREGNATO; MUTTI, 
2006, p. 682), foram analisados buscando-se descrever e interpretar os eventos acidentários nos quais os conteúdos similares foram agrupados em duas seções temáticas: a primeira trata do trabalho desenvolvido pelo acidentado durante sua vida laboral e a segunda, das circunstâncias da morte, no trânsito, por homicídio e por óbito no ambiente de empresa ou afim.

O projeto foi aprovado pelo Comitê de Ética em Pesquisa com Seres Humanos do Instituto de Saúde Coletiva da Universidade Federal da Bahia - UFBA (registro CEP: 033-04).

\section{Resultados e discussão}

Entre os 91 óbitos, o maior envolvimento foi de homens casados, com idade média de 38 anos e baixa escolaridade ( $1^{\circ}$ grau/grau fundamental), que morreram no exercício do trabalho ou no seu trajeto, em sua maior parte no "espaço da rua”. A descrição mais detalhada dessas características é objeto de outro artigo, de natureza quantitativa (LACERDA; FERNANDES; NOBRE, 2014).

\section{A caracterização do trabalho desenvolvido pelo acidentado}

Revelou-se que o vínculo empregatício com carteira de trabalho assinada não foi a experiência mais comum entre as vítimas, no entanto, embora o trabalho regulamentado fosse condição de uma pequena parte dos trabalhadores, as condições para o seu exercício são evidenciadas na fala de uma familiar:

\begin{abstract}
[...] meu irmão foi motoboy entregador de jornais por nove anos, com carteira de trabalho assinada [...]. A cada dia que passava, as condições de trabalho pioravam, além do acúmulo de folgas que ele não conseguia tirar por não haver pessoas para substituir ele [...]. O acidente ocorreu às 4:30 h da manhã, quando ele estava treinando uma pessoa que iria tirar a sua folga, tentou desviar do caminhão parado e colidiu com outra moto. (Caso 67)
\end{abstract}

A despeito do aumento do emprego formal, como ocorreu em 2000, conforme ressalta Alves (2002, p. 82), "evidenciou-se a precarização do salariato no Brasil” no mesmo período. Para o autor, “[...] embora tenha ocorrido o crescimento do emprego formal, a tendência de precarização da estrutura ocupacional manteve-se em muitos aspectos”. E a informalidade emerge de forma relevante nas narrativas:

Ele estava trabalhando na "feira do rolo", era vendedor ambulante desde os oito anos, iniciou vendendo amendoim no "Comércio", nunca trabalhou com carteira de trabalho [...] (Caso 91)

O trabalho na informalidade se refere a diferentes atividades não regulamentadas pelo Estado (KALLEBERG,
2009). O trabalho informal é entendido por Nobre (2007, p. 56) como aquele no qual há "[...] ausência de relações formais de emprego, que resultam em maior vulnerabilidade dos trabalhadores inseridos em trabalhos instáveis e desprotegidos, sem segurança social e incapazes de suprir as necessidades básicas da família”. O trabalho precário e a insegurança das relações de trabalho podem ser observados na fala do familiar:

\section{[...] Meu marido era pintor de automóveis, realizava serviços de chaparia e pintura de autos. Reclamava do atraso no pagamento dos serviços prestados e por isso pensava em trabalhar por conta própria. [...] $O$ patrão somente assinou a carteira de trabalho após o óbito, registrado como novo funcionário. O patrão não recolhia o que descontava do salário dele e só tentou regularizar a situação após o seu falecimen- to. (Caso 25)}

Essas atividades não regulamentadas incluem também sujeitos denominados trabalhadores por conta própria, em sua maior parte sem estabilidade trabalhista e/ou segurança previdenciária, tais como vendedores ambulantes, pequenos varejistas ou artesãos, taxistas, barbeiros, cabeleireiros, donos de pequenos estabelecimentos, os quais oferecem vários tipos de serviço pessoal (KALLEBERG, 2009). A fala de um familiar evidencia esse tipo de inserção:

\section{[...] minha mãe trabalhava num bar de sua pro- priedade, por conta própria [...], o imóvel era alu- gado, servia refeições e bebidas [...], ela reclamava do desgaste, pois o trabalho era bastante cansativo no bar [...], nunca trabalhou com carteira assinada. (Caso 53)}

Entre as vítimas houve diferentes tipos de inserção de trabalhadores, com vínculo formal ou informal de trabalho, trabalhadores por conta própria ou autônomos, servidores públicos estatutários e/ou militares, no entanto o que se evidenciou foi a marcante presença do trabalho precário, aquele realizado em condições nas quais a morte representou evento previsível. $\mathrm{O}$ depoimento da esposa de um trabalhador evidencia a intensificação (da exploração) e a insegurança no trabalho e os impactos desse trabalho na saúde:

Estava há três dias trabalhando, cerca de 55 horas,
como armador e supervisor de armação no Porto de
Salvador [...]. Não tinha horas fixas, só tinha hora
para sair de casa. Dependia do navio [...], ele re-
clamava, pois não tinha tempo para ninguém; não
participava de eventos familiares [...], gostava do
que fazia, mas achava estressante, tinha muita as-
sadura, afta, não tinha horário para dormir, comer
[...], a empresa é culpada [...], não respeita os limi-
tes de cada trabalhador. Ele foi esmagado por um
contêiner. (Caso 65)

Nesse caso acima, as condições de trabalho precárias são vistas no cotidiano do trabalho regulamentado com carteira assinada. Mas essas condições são especialmente flagrantes entre aqueles trabalhadores não regulamentados, os trabalhadores informais que, 
segundo Ludermir (2005, p. 199), formam um grupo de trabalhadores por conta própria, sem carteira assinada, "uma categoria desprivilegiada, sem qualquer proteção da legislação trabalhista” e sem direito aos benefícios sociais e previdenciários.

Evidenciou-se a presença de extensas jornadas de trabalho, adotadas no sentido de complementar os baixos salários ou melhorar a renda. Sobre esse fato, a esposa de um trabalhador afirma:

Ele era motorista de táxi, autônomo, dirigia táxi de terceiro [...], pagava diária [...], trabalhava à noite, todas as noites, das $19 \mathrm{~h}$ às $6 \mathrm{~h}$ da manhã seguinte [...]. Queria voltar a ser segurança, mas não tinha curso técnico [...]. Considerava muito desgastante dirigir a noite toda. (Caso 26)

Apesar de classificado como trabalhador autônomo, a extensão da jornada não era apenas uma entre muitas escolhas. Estender a jornada era a estratégia possível para auferir uma renda mínima necessária, pois embora autônomo, o trabalhador, taxista, utilizava automóvel de terceiro, a cujo proprietário ele pagava uma parte do que recebia, como "diária”.

Sobre o espaço da rua como local de ocorrência dos AT, chama atenção que esse não mais se constitui apenas como principal local dos AT de trajeto, mas emerge fortemente como local de ocorrência do AT típico, o que pode configurar um fato novo no estudo dos AT.

Cerqueira (2000, p. 57-58) caracteriza a rua “[...] como espaço que absorve os trabalhadores excedentes da reestruturação produtiva e reproduz a exclusão com suas teias laborais e relações de poder e legalidade”. Ilustrando essa situação, o irmão de um trabalhador descreve:

Ele era segurança de rua à noite na "Sussuarana" [bairro], trabalhava como biscate; os moradores de uma rua pagavam diretamente a ele uma taxa, o vínculo era por conta própria, autônomo [...]. Ele reclamava do trabalho que era muito perigoso! [...] Saiu nota no jornal - Segurança clandestino assassinado com 12 facadas. (Caso 48)

Os novos modos de trabalhar e de viver implicam a necessidade de dirigir um olhar mais atento para esses trabalhadores que ocupam as ruas como novo espaço de trabalho. Carneiro (2000) contribui com a discussão quando afirma que os trabalhadores no exercício de suas atividades no ambiente da rua sofrem mais violência no trabalho do que aqueles em ambiente de empresas. Como relata a tia de uma trabalhadora:

Ela era vendedora ambulante de queijo coalho em praias de Salvador e Camaçari e fazia biscates como ajudante de cozinha em barracas de praia [...]. Nunca trabalhou com carteira assinada. Ela queria apenas um trabalho fixo [...]. Foi atropelada indo para o trabalho. (Caso 66)
As características ocupacionais revelam o quanto os trabalhadores são afetados pela precariedade tanto na inserção no mundo do trabalho quanto no curso do trabalho desenvolvido. A ocupação mais frequente das vítimas foi a de pedreiro, seguida da de comerciante, vigilante, motoboy, motorista e outras ocupações, incluindo vínculos informais e formais, e trabalhadores por conta própria ou autônomos (LACERDA; FERNANDES; NOBRE, 2014).

Segue o relato de um familiar acerca da inserção precoce e precária no mercado de trabalho: Começou a trabalhar aos sete anos, vendia picolé no trem, era ambulante [...]. Foi encontrado na maré, onde catava siri, afogado. (Caso 1)

De acordo com Alberto (2002), o trabalho precoce está relacionado a diversos fatores, sociais, políticos e econômicos, e sua origem, possivelmente relacionada à pobreza familiar. A inserção precoce do trabalhador no mercado informal ou no trabalho por conta própria surge como meio de auxiliar a sobrevivência do núcleo familiar.

Uma das implicações nesse cotidiano repleto de adversidades é a invisibilidade do sujeito enquanto trabalhador. A oportunidade do trabalho precário, incerto, acaba sendo aceita sob quaisquer circunstâncias pelo trabalhador, já que essa oportunidade de trabalho, o "biscate", pode representar a única condição para assegurar a sua sobrevivência e da sua família.

Evidenciou-se nas narrativas a situação de trabalhador formal que, além desse vínculo, ocupava-se, no tempo que seria livre, com um trabalho para ajudar membro da família ou com outro vínculo informal. Nesse trabalho precário, o que se viu não foi o fenômeno contemporâneo de invasão do tempo livre pelo empregador, com o serviço em domicílio ou o serviço que não respeita a jornada de trabalho regular. $\mathrm{O}$ que se evidenciou para boa parte dos trabalhadores foi a ocupação de todo o tempo da vida com os trabalhos ou "biscates" que são assumidos para assegurar a sobrevivência. Não se pode falar aqui de livre escolha; o que se viu foi uma situação de vida que impõe a aceitação de qualquer oferta de trabalho, a qualquer tempo e hora, para assegurar a sobrevivência imediata. Como relata a mãe de um trabalhador:

Meu filho era pedreiro [...], fazia construção de casas
com pouca frequência, mas quando trabalhava era
durante todo o dia [...] e fazia também biscates como
carregador de mudança, por conta própria. Ele ga-
nhava uns trocados ajudando conhecidos e no dia
do acidente ele estava fazendo um desses traba-
lhos. Dizia que não pagavam o equivalente ao servi-
ço dele [...]. Estava fazendo uma mudança quando
atravessou a rua carregando um vidro e foi atrope-
lado por um ônibus. (Caso 2)

Nesse sentido, elimina-se a fronteira entre tempo livre e tempo ocupado. Segundo afirmam Alves 
e Tavares (2006, p. 430), a propósito dessa força de trabalho informal, pauperizada nos períodos de acúmulo de atividades laborais como "força de trabalho eventual" e "não paga", o tempo despendido para garantir a sobrevivência e reprodução da força de trabalho familiar nem é entendido como "[...] um tempo racional de trabalho, apesar de absorver dias úteis, fins de semana, noites e feriados". Tal realidade pode ser observada na fala do familiar:

Ele trabalhava como operador de estação de tratamento de efluentes de uma empresa terceirizada e cuidava da manutenção do tanque do aeroporto para não poluir o rio; era empregado com carteira assinada [...]. Tinha outra ocupação como servente de pedreiro [...]. Ele vinha da casa do pai, onde estava ajudando na construção de uma casa, quando foi atropelado. (Caso 20)

Diante do medo confessado, do sofrimento pela perda, da exclusão social atrelada à desinformação sobre a existência de direitos previdenciários (pensão por morte), trabalhistas (direito de segurança no trabalho, seguro acidente de trabalho) e assistenciais (seguro DPVAT - seguro obrigatório de acidentes da seguradora do veículo, auxílio funeral), as famílias expressam a impotência frente ao comportamento omisso das empresas, à impunidade dos agressores, à insegurança e/ou à inoperância das instituições públicas. Tal fato pode ser constatado no depoimento da mãe de um trabalhador, destacando a informalidade e privação das leis trabalhistas e previdenciárias:

Ele tinha 24 anos e trabalhava como cobrador de Topic no transporte de passageiros e também como ajudante de pedreiro; nunca trabalhou com carteira assinada; fazia biscates; não era fixo [...], reclamava do salário que era pouco [...]. Não procurei o INSS, pois ele não contribuia, não recebemos pensão [...]. Fiquei com medo de procurar a polícia, pois tenho outros filhos [...]. Ele reclamou com um rapaz que desceu de outra Topic e urinou na frente de duas moças e começou a brigar [...]. A polícia chegou, correu atrás e deu tiros [...]. Ele correu [...]. É uma dor perder um filho e ainda mais com essa perversidade [cortaram os pulsos, arrancaram unha, quebraram os dentes e deram tiro no ouvido] que foi feita. (Caso 19)

A garantia social do benefício, mesmo para "aqueles que acreditavam estar protegidos" (MENDES; WÜNSCH, 2009, p. 246) são constantemente ameaçados. Ilustrando essa situação, um entrevistado afirma:

Ela trabalhava há seis anos e sete meses como técnica em EEG, em consultório médico, com carteira assinada [...] e foi atropelada por um ônibus no caminho do trabalho. Ela queria conseguir alguma coisa melhor na área de saúde [...]. Não recebo pensão por morte. Alegaram que ela não estava no percurso do trabalho; os peritos não colocaram no laudo que foi acidente de trabalho e sim um atropelamento. Muita burocracia, falta de informação e de organização [...] (Caso 4)
Compreender a dinâmica social dos acidentes relacionados ao trabalho significa desvelar a "[...] história de vida e de morte no trabalho, de pessoas pertencentes a parcelas da sociedade que ficaram à margem das informações oficiais" (MENDES, 2003, p. 18).

\section{Circunstâncias da morte}

Nesta seção, as circunstâncias da morte mais frequentes são apresentadas baseando-se na sua ocorrência: acidentes de trânsito, homicídios e acidentes no ambiente de empresa ou afim.

\section{A morte no trânsito}

Os acidentes de trânsito são eventos de grande magnitude, tanto do ponto de vista sanitário como do ponto de vista social e econômico (BRASIL, 2005).

As formas de tornar invisíveis as mortes relacionadas ao trabalho dentre as causas externas são diversificadas e a interface do acidente de trânsito com o trabalho não é simples, o que acentua a subnotificação desses eventos como AT. O local de realização do trabalho para muitos dos casos estudados foi a via pública, ou o "espaço da rua", que não constituiu apenas a via de percurso de casa para o trabalho. Evidenciou-se a necessidade de descrever as circunstâncias dessa exposição do trabalhador nesse ambiente externo de trabalho, muitas vezes em condições precárias.

A morte do trabalhador no trânsito não expressa apenas a importante questão geral de saúde pública vinculada à morte no trânsito mas revela, além disso, as condições nas quais está ocupada uma grande parte de trabalhadores e, portanto, exposta e mais vulnerável no seu cotidiano laboral, pela precariedade dos meios de deslocamento para o trabalho ou pela ausência da segurança no exercício do trabalho no "espaço da rua”. Essa abordagem do caráter ocupacional das mortes no trânsito vai ao encontro da reflexão proposta por Mendes (2003, p. 70), ao afirmar que estudar o trabalho e suas consequências "[...] implica no exame não somente de questões diretamente vinculadas a ele, mas da sua articulação com outras lógicas sociais". Além disso, como uma nova característica do mundo do trabalho, conforme já referido, vê-se a retirada do trabalhador do espaço das fábricas e sua exposição em áreas urbanas compartilhadas com toda a sociedade (OLIVEIRA; NUNES, 2008).

Em relação às vítimas e aos veículos envolvidos nos acidentes, o atropelamento do pedestre emerge em narrativas de familiares, como a que se segue, em que a mãe de um trabalhador relata sua dor: 
Culpa do motorista, que estava dopado. O rapaz tinha 17 anos. Gostaria de ter uma arma para matar o rapaz que atropelou o meu filho e a tia dele, que comprou o carro envolvido no atropelamento. (Caso 8)

Para Faria e Braga (1999), as ações voltadas para a redução de acidentes têm privilegiado o trânsito dos veículos motorizados, o que deixa os pedestres em desvantagem em relação aos programas desenvolvidos para os motoristas.

De um modo geral, os familiares entrevistados afirmaram, ao serem inquiridos sobre a causa principal e responsabilidade do acidente, que o problema não é o veículo em si ou as condições da via pública, mas a imprudência e irresponsabilidade do condutor do veículo. Não se pode omitir, no entanto, que o AT no trânsito pode também resultar do estresse e fadiga física experimentados pelo motorista profissional, submetido a extensas jornadas de trabalho e relações de trabalho inadequadas.

Evidenciou-se o motoboy entre as vítimas de AT, podendo representar uma ocupação no mundo do trabalho que tem se ampliado a cada dia. Os motoboys representam uma população com grande risco de envolvimento em acidentes de trânsito devido às constantes exigências do seu trabalho (SILVA et al., 2008). Daí se originam diversas insatisfações com a profissão, marcada pelos riscos, desgaste no trânsito e péssimas condições de trabalho:

Queria mudar de trabalho! Reclamava dos riscos e do pouco faturamento como motoboy, ele estava desempregado há três meses, entregava refeições que a mãe fazia para vender, com motocicleta [...]. No dia do acidente, ele saiu para entregar as refeições [...] (Caso 33)

\section{O trabalhador como vítima de homicídio}

Refletir sobre a intensificação da violência, com destaque para os homicídios, é um exercício necessário na sociedade brasileira.

Os efeitos desse fenômeno têm repercutido na Saúde do Trabalhador (MINAYO-GOMEZ; THEDIM-COSTA, 1999). A filha de um trabalhador, agente de saúde, relata a sua experiência a respeito: "Meu pai estava dentro do ônibus, indo para o trabalho, foi vítima de bala perdida de um assalto" (Caso 5).

O homicídio ocorrido em tentativas de assalto ou roubo evidencia-se nos dizeres de familiares, que fazem referência à situação:

Ele era vigilante da rua, pago pelos moradores, estava voltando do trabalho, como segurança, na madrugada [...]. Quando estava chegando em casa, mataram-no a tiros [...]. Consideramos que foi assalto. (Caso 22)
Ele trabalhava como motorista de táxi [...], autônomo, pagava diárias em carros de terceiros. Queria ser motorista de ônibus. Reclamava da carga horária [muito acima do permitido], insegurança e brigas com colegas de trabalho na disputa de pontos [...]. Foi assassinado a tiros, vítima de assalto. (Caso 85)

O risco de assalto expõe, particularmente, o agente de segurança e, concordando com Silveira et al. (2005), expõe também o motorista. Essa população de trabalhadores não possui uma proteção adequada e a relação existente entre o óbito e o trabalho que é realizado no "espaço da rua" é muitas vezes pouco clara, dificultando desvendar as reais circunstâncias do óbito do trabalhador e facilitando sua subnotificação como AT.

No caso dos homicídios, constitui uma legítima demanda social o esforço para conhecimento das reais circunstâncias da morte, tendo em vista que as vítimas muitas vezes são trabalhadores inseridos no mercado informal, em atividades laborais não reconhecidas socialmente (MINAYO GOMEZ; THEDIM-COSTA, 1999). Investigar essas mortes na sua relação com o trabalho evidencia, muitas vezes, a gravidade da exclusão do direito ao trabalho decente.

\section{$O$ acidente no ambiente de empresa ou afim}

O estabelecimento ou ambiente específico de trabalho pode não ter sido uma empresa, mas uma obra de construção civil de um familiar, por exemplo. É possível relacionar as situações de insegurança e risco ocupacional nos espaços de trabalho no relato de um familiar:

\begin{abstract}
Meu marido trabalhava como operador de utilidade em uma indústria química [...], ele falava muito dos problemas com a caldeira. Falava muito da gestão da empresa. Fora que estava afetando a saúde dele; já estava prejudicada [...]. Os outros funcionários devem estar passando ou sofrendo as mesmas pressões. Nem fechar a empresa para buscar solucionar o problema que levou ao acidente... Isso serviria para eles sentirem no bolso... mas logo substituiu a caldeira e nada parou [...]. A empresa só fez a parte dela. Matou ele e enterrou. (Caso 16)
\end{abstract}

Nobre (2007, p. 23) alerta que embora todo AT seja uma forma de violência, essa se apresenta de duas diferentes formas na determinação daquele: o AT pode ser consequência da "violência (estrutural) explícita, urbana, expressão das desigualdades sociais, da miséria, da discriminação, do racismo e da pobreza", ou o AT pode ser:

[...] resultante das relações de poder desigual entre empregadores e trabalhadores; quando os primeiros, ao manter condições precárias e inseguras de trabalho e relações de trabalho autoritárias, ao privilegiar demandas econômicas, de produtividade e 
lucratividade, colocam a vida dos trabalhadores em segundo plano, resultando em acidentes de trabalho no exercício de suas atividades e funções específicas. (NOBRE, 2007, p. 23)

A fala do familiar ilustra a violência exercida pela manutenção de condições sabidamente adversas de trabalho. No caso, havia uma caldeira em condições irregulares de funcionamento, com grande probabilidade de causar acidente, mas a situação foi mantida sem solução pela gestão da empresa. Isso resultou na morte do trabalhador.

Em relação à ocupação exercida no dia do acidente, chama atenção a inserção precária de pedreiros, ajudantes e serventes da construção civil, sem carteira assinada, o que se revela no depoimento do familiar:

Estava na Travessa 11 de Janeiro, bairro do Tancredo Neves. Ele estava trabalhando, colocando longarina (liga de ferro com concreto), para armar a laje de uma casa de primeiro andar. Era o primeiro dia de serviço. Iniciou às 8 horas e por volta das 9 horas ocorreu o fato. Ele colocou a longarina molhada e a força do fio de alta tensão da rua, com 11 mil volts, puxou ele, levando-o à morte. Foi fatal! (Caso 50)

Os acidentes identificados permitem reafirmar que os riscos não são inerentes ao trabalho, na verdade estão relacionados com a organização do trabalho e/ou decorrem de uma cultura que minimiza os aspectos de segurança e de preservação da vida humana.

\section{Considerações finais}

As circunstâncias das mortes de trabalhadores jovens, em idade produtiva, responsáveis pelo sustento da família, revelam as condições de trabalho precário. A isso se alia a relevância da violência social e sua relação com o AT.

O mundo do trabalho determina novas modalidades de exposição ocupacional do trabalhador ao AT, agora não mais vinculado apenas às características dos espaços internos de trabalho e aos riscos tradicionalmente elencados, decorrentes de instalações, ferramentas, equipamentos e maquinários no mundo industrial ou no setor de serviços. O espaço da rua traz, por exemplo, a exposição à violência urbana, ao acidente de trânsito como riscos potenciais de acidente de trabalho. O exercício das ocupações nesse "espaço da rua” incorpora às ocupações mais tradicionais de condutores de veículos novas ocupações vulneráveis aos acidentes no trânsito e à violência crescente do espaço urbano. Nesse caso, ressalta-se não somente o deslocamento para o trabalho em condições precárias, mas o exercício do trabalho nas ruas, como nos casos do vendedor ambulante, do motoboy e das novas ocupações de condutores de veículos para transporte de pessoas no espaço urbano, como motoristas de pequenos veículos de transporte coletivo e seus auxiliares, sem vínculos formais de trabalho e em condições precárias. O AT não é mais vinculado apenas às características dos espaços internos.

A luta pela sobrevivência, no contexto de grande exclusão do mercado de trabalho formal, gera inúmeras formas de ocupação que se materializam nos "biscates", inventados e reinventados a cada dia. A invasão de todo o tempo existente pelo trabalho, precário e informal, se associa a uma supressão da fronteira entre tempo de vida no trabalho e tempo de vida livre.

Apesar do AT com óbito constituir uma relevante causa de morte da população trabalhadora, persistem sérios problemas em relação à produção e à qualidade desses dados nos sistemas de informação em saúde. A investigação de óbitos incorporando a técnica da autópsia verbal (LACERDA; FERNANDES; NOBRE, 2014) pode representar uma importante contribuição na produção de informações complementares sobre as causas externas de óbito, especialmente os acidentes de trabalho. Trata-se de um instrumento ainda pouco conhecido no âmbito da Saúde do Trabalhador, que pode contribuir para a redução da subnotificação e para desnudar as circunstâncias envolvidas na morte do trabalhador, permitindo identificar fatores condicionantes e determinantes da situação de saúde dos trabalhadores, elementos fundamentais para o planejamento das ações de promoção e proteção da saúde, bem como de outras políticas setoriais.

A prevenção das mortes e violências no trabalho requer a participação dos atores sociais envolvidos, sindicatos, trabalhadores, empresas e empreendedores, além da articulação entre órgãos públicos, como da saúde, trabalho, trânsito e segurança pública. As políticas de saúde devem articular as ações de promoção à saúde dos trabalhadores com aquelas de combate à violência, bem como com as políticas de segurança pública, de planejamento e transporte urbano. Ações integradas, com a perspectiva de ampliar o diálogo entre setores, a construção de mecanismos e estratégias solidárias e cooperativas são fundamentais para a efetividade das políticas de promoção e proteção da saúde de todos os trabalhadores.

Assim, o papel do poder público não se restringe à regulação das relações trabalhistas formais; devem ser garantidas ações efetivas de regulação, monitoramento e fiscalização das condições de trabalho, sejam elas de atividades formais ou informais, em ambientes delimitados ou "no espaço da rua". Ou seja, promoção de ações que transformem o trabalho precário em trabalho decente, digno, protegido e com garantia de suporte social para o trabalhador. 


\section{Contribuições de autoria}

Lacerda, K. M. e Fernandes, R. C. P.: foram responsáveis pela concepção do estudo, pela análise dos dados, elaboração do artigo e pela revisão final do manuscrito. Nobre, L. C. C.: foi responsável pela elaboração do instrumento, pela etapa de coleta dos dados e pela revisão final do manuscrito. Pena, P. G. L.: participou da análise dos dados.

\section{Referências}

ALBERTO, M. F. P. A dimensão subjetiva do trabalho precoce de meninos e meninas em condição de rua em João Pessoa, PB. 2002. 305 f. Tese (Doutorado em Sociologia) - Universidade Federal de Pernambuco, Recife, 2002.

ALVES, G. Trabalho e sindicalismo no Brasil: um balanço crítico da "Década Neoliberal” (1990-2000). Revista de Sociologia e Política, Curitiba, n. 19, p. 71-94, 2002. http://dx.doi.org/10.1590/S010444782002000200006.

ALVES, M. A.; TAVARES, M. A. A dupla face da informalidade do trabalho: "Autonomia" ou precarização. In: ANTUNES, R. (Org.). Riqueza e miséria do trabalho no Brasil. São Paulo: Boitempo, 2006. p. 425-444.

BARDIN, L. Análise de conteúdo. Lisboa: Edições 70, 2009.

BRASIL. Ministério das Cidades. Departamento Nacional de Trânsito - DENATRAN. Frota de veículos. Brasília: DENATRAN, 2005. Disponível em: <http:// www.denatran.gov.br/frota.htm>. Acesso em: 28 jun. 2011.

. Ministério da Saúde. Manual para investigação do óbito com causa mal definida. Brasília: Ministério da Saúde, 2008.

. Ministério da Previdência Social. Anuário Estatístico da Previdência Social 2009. 2009. Disponível em: <http://www.mpas.gov.br> . Acesso em: 21 set. 2011.

Ministério da Previdência Social. Anuário Estatístico de Acidentes do Trabalho. 2012. Disponível em: < http://www.previdencia.gov.br/estatisticas > . Acesso em: 20 ago. 2014.

CAREGNATO, R. C. A.; MUTTI, R. Pesquisa qualitativa: análise do discurso versus análise de conteúdo. Texto \& Contexto - Enfermagem, Florianópolis, v. 15, n. 4, p. 679-684, 2006. http:// dx.doi.org/10.1590/S0104-07072006000400017.

CARNEIRO, S. A. M. Trabalho e violência: relação de proximidade da violência a trabalhadores durante a jornada de trabalho, na Zona Norte de São Paulo, em 1998. 2000. 149 f. Dissertação (Mestrado em Saúde Pública) - Faculdade de Saúde Pública, Universidade de São Paulo, São Paulo, 2000.
CERQUEIRA, M. B. Os guardiões do tempo sobrevivem à cidade veloz: trabalho informal e saúde, dimensões da exclusão social. 2000. 145 f. Dissertação (Mestrado em Sociologia) - Universidade Estadual de Campinas, Campinas, 2000.

CORDEIRO, R. et al. Subnotificação de acidentes do trabalho não fatais em localidade do Estado de São Paulo. Revista de Saúde Pública, São Paulo, v. 39, n. 2, p. 254-260, 2005. http://dx.doi.org/10.1590/S003489102005000200017. PMid:15895146

FARIA, E. O.; BRAGA, M. G. C. Propostas para minimizar os riscos de acidentes de trânsito envolvendo crianças e adolescentes. Ciência \& Saúde Coletiva, Rio de Janeiro, v. 4, n. 1, p. 95-107, 1999. http://dx.doi.org/10.1590/S1413-81231999000100008.

GOMEZ, C. M. Violência no trabalho. In: BRASIL. Ministério da Saúde. Impacto da violência na saúde dos brasileiros. Brasília: Ministério da Saúde, 2005. p. 241-278.

HENNINGTON, E. A.; CORDEIRO, R.; MOREIRA FILHO, D. C. Trabalho, violência e morte em Campinas, São Paulo, Brasil. Cadernos de Saúde Pública, Rio de Janeiro, v. 20, n. 2, p. 610-617, 2004. http://dx.doi.org/10.1590/S0102-311X2004000200031. PMid:15073643

KALLEBERG, A. L. O crescimento do trabalho precário: um desafio global. Revista Brasileira de Ciências Sociais, São Paulo, v. 24, n. 69, p. 21-30, 2009. http://dx.doi.org/10.1590/S010269092009000100002.

LACERDA, K. M.; FERNANDES, R. C. P.; NOBRE, L. C. C. Acidentes de trabalho fatais em Salvador, BA: descrevendo o evento subnotificado e sua relação com a violência urbana. Revista Brasileira de Saúde Ocupacional, São Paulo, v. 39, n. 129, p. 63-74, 2014. http://dx.doi.org/10.1590/0303-7657000064812.

LOURENÇO, E. Â. S. Na trilha da saúde do trabalhador: a experiência de Franca/SP. Franca: UNESP, 2009.

LUDERMIR, A. B. Associação dos transtornos mentais comuns com a informalidade das relações de trabalho. Jornal Brasileiro de Psiquiatria, v. 54, n. 3, p. 198-204, 2005.

MACHADO, M. N. M. Entrevista de pesquisa: a interação entrevistador / entrevistado. 1991. $151 \mathrm{f}$. Tese 
(Doutorado em Enfermagem) - Universidade de Belo Horizonte, Belo Horizonte, 1991.

MENDES, J. M. R. O verso e o anverso de uma história: $o$ acidente e a morte no trabalho. Porto Alegre: EDIPUCRS, 2003.

MENDES, J. M. R.; WÜNSCH, D. S. Trabalho, classe operária e proteção social: reflexões e inquietações. Revista Katálysis, Florianópolis, v. 12, n. 2, p. 241-248, 2009. http://dx.doi.org/10.1590/S141449802009000200014.

MINAYO-GOMEZ, C.; THEDIM-COSTA, S. M. F. Precarização do trabalho e desproteção social: desafios para a saúde coletiva. Ciência \& Saúde Coletiva, Rio de Janeiro, v. 4, n. 2, p. 411-421, 1999. http://dx.doi. org/10.1590/S1413-81231999000200015.

MINAYO-GOMEZ, C.; MACHADO, J. M. H.; PENA, P. G. L. (Org.). Saúde do trabalhador na sociedade brasileira contemporânea. Rio de Janeiro: FIOCRUZ, 2011.

NOBRE, L. C. C. Trabalho precário e mortes por acidentes de trabalho: a outra face da violência e a invisibilidade do trabalho. 2007. $283 \mathrm{f}$. Tese (Doutorado em Saúde Coletiva) - Universidade Federal da Bahia, Salvador, 2007.
OLIVEIRA, R. P.; NUNES, M. O. Violência relacionada ao trabalho: uma proposta conceitual. Saúde e Sociedade, São Paulo, v. 17, n. 4, p. 22-34, 2008. http:// dx.doi.org/10.1590/S0104-12902008000400004.

RUIZ, M. T.; BARBOZA, D. B.; SOLER, Z. A. S. G. Acidentes de trabalho: um estudo sobre esta ocorrência em um hospital geral. Arquivos de Ciências da Saúde, São José do Rio Preto, v. 11, n. 4, p. 119124, 2004.

SILVA, D. W. et al. Perfil do trabalho e acidentes de trânsito entre motociclistas de entregas em dois municípios de médio porte do Estado do Paraná, Brasil. Cadernos de Saúde Pública, Rio de Janeiro, v. 24, n. 11, p. 2643-2652, 2008. http:// dx.doi.org/10.1590/S0102-311X2008001100019. PMid:19009144

SILVEIRA, C. A. et al. Acidentes de trabalho e trânsito entre motoristas atendidos em serviço de emergência. Revista de Enfermagem UERJ, Rio de Janeiro, v. 13, n. 1, p. 44-50, 2005.

WALDVOGEL, B. C. A população trabalhadora paulista e os acidentes do trabalho fatais. São Paulo em Perspectiva, São Paulo, v. 17, n. 2, p. 42-53, 2003. http://dx.doi.org/10.1590/S0102-88392003000200006. 